\title{
Construction and Application of the Design Method of Cultural Products Based on the Meme of Liao dynasty ceramics
}

\author{
Yue $\mathrm{Zhu}^{1,2^{*}}$ and Cheng-lein TENG ${ }^{2}$ \\ ${ }^{1}$ Shenyang Aerospace University, Shenyang, Liaoning, 110136, China \\ ${ }^{2}$ Asia University, Taizhong, Taiwan, 41354, China
}

\begin{abstract}
A design method of one cultural product based on the meme of artifacts was constructed and applied to the development and design of cultural products. Firstly, the paper puts forward that the outer "tangible" level of the "spatial perspective" of culture corresponds to the dominant meme, as well as the mid "behavioral" level and Inner "intangible" level correspond to the hidden meme according to the theories of meme and the "spatial perspective" of culture. What's more, the meme was extracted according to the appearance of Liao dynasty ceramics and related research literature. Secondly, based on the extracted meme of Liao dynasty ceramics, the design method of cultural products was constructed by applying the theoretical framework two orders of the signification of Roland Barthes Semiotics to explore the extended cultural meaning of meme and apply its translation to the design of cultural products. The design method of cultural products constructed by this Institute is more inclusive of the intrinsic level of artifacts than that in the past, which only created cultural products that focus on the physical representation of the visual elements. It is an attempt to provide designers of cultural products and students with design background with a design method of cultural products for reference.
\end{abstract}

\section{Introduction}

With the vigorous development of cultural and creative industries, the relationship between the culture and design becomes closer and closer. For design, culture increases the core value of products and stimulates the innovation process of products; for culture, design is the driving force of cultural development[1]. The design of cultural and creative products is a design activity integrating creativity, culture and aesthetics. It depends on human's experience, creative thinking and related cultural knowledge, especially cognition and understanding of ancient artifacts[2]. Relevant researchers believe that in addition to their practical function, through the change of forms and decorative patterns, those ancient artifacts can convey cultural feelings and spiritual implications. Many cultural and creative designers tend to find inspiration from the ancient artifacts of my country and integrate cultural elements into the product design to convey cultural value[3]. Therefore, in the design creation of cultural and creative products, using the cultural features contained in the ancient artifact itself as design source, not only can enhance the presentation of aesthetic feeling of cultural and creative products, but also can convey emotion and cultural connotation, stimulate consumers' pleasure and create unique cultural and creative products with national characteristics.
The ceramics in the Liao dynasty are the first officially supported system ceramic production system in northern China; In ceramic technology, it inherited and borrowed the skills of Tang and Song and in shape and decoration, it imitates the style of Tang Tri-Color Glazed Ceramics or song Ding kiln and Cizhou kiln[4]; absorbing many kinds of cultural factors and integrating them into the nomadic life of Qidan people, the unique shape in the Liao dynasty was formed, such as cockscomb pot, phoenix bottle, begonia plate, which plays an important role in the history of Chinese ceramics[5]. With the ceramics in the Liao dynasty as the research object, starting from the perspective of meme, based on the two orders of signification in Roland Barthes semiotics, this research discusses the cultural connotation and extension significance of dominant meme and recessive meme of the ceramics in the Liao dynasty, and visual design and cultural and creative product design practice are carried out respectively so as to construct a kind of cultural and creative product mode based on different kinds of meme.

\section{Relevant research background of meme}

The British biologist Richard Dawkins first mentioned the word "meme" in his works The Selfish Gene[6]. He held that there were similarities between meme and biological gene in the process of gene transmission and analogizes the transmission of culture according to the way of gene reproduction. He pointed out that though

\footnotetext{
*Corresponding author's e-mail: 171126794@qq.com
} 
human beings were built as gene machines, they were cultivated as meme machines. In 1998, the word "meme" was included in the Oxford English Dictionary and explained as "the basic unit of culture, pass on by nonhereditary means, especially imitation.'[7]. At present, the meme research based on Chinese culture mainly concentrate on the field of philosophy and in the perspective of thinking model. There are still others studying in the perspectives of Ethnology and Anthropology as well as the perspective of cultural structure, and are studies on the nature of cultural ontology. In the early 21 st century, the Institute of Philosophy of Chinese Academy of Social Sciences took "meme" as a key research project and held that there was also a theory of sociocultural genes called S-cDNA beyond biological gene. However, in recent years, there were still some researches introducing the concept of meme in the design field. For example, Liu [8] introduced the gene concept of Biology and construct "Gene identification" and "gene map" of Chinese traditional settlement landscape. Gou et al[9]constructed Banpo pottery culture gene library, including: three parts: pattern gene, color gene and shape gene, which are applied to design and creation. Therefore, the researches on meme in the design field are mostly conducted from the perspectives of cultural gene recognition and construction of gene map and database, etc.

\section{Design method of cultural and creative products}

Lin[1] held that the cultural and creative product is a kind of process of reflection or examination of cultural identity, which meets the cultural and aesthetic needs of consumers through integrating cultural features into product design. At present, the research on the design method of cultural and creative products is as follows: Wang \& Hong[10]combined metaphor theory of structural mapping, and through similarity judgment, feature mapping mode and other ways, put forward the design method suitable for cultural and creative products. Zhang, Liu \& Xiong[11]summarized three levels of cultural image to use the method of situational story to design the cultural and creative products based on the culture of Taiya's tattoo. Zhu \& Luo[12]put forward the interpretation model of design symbols of cultural relic elements based on the research method of cultural relic element reconstruction in Design Semiotics. Wang \& Wei[13]combined the triangle pattern of Banpo painted pottery and modern constitution to arrange the unit patterns and apply them to cultural and creative product design. With reference to the above literature, the research finds that metaphorical method, situational story method, semiotics, formal composition method and other design methods are the means and methods of effectively translating cultural connotation into creative design. Bu there are few literatures, from the perspective of meme, discussing the design methods and modes of cultural and creative products in view of the cultural characteristics and connotations of different cultural levels.

\section{Roland Barthes semiotics- two orders of signification}

Roland Barthes held that the expression of all culture phenomena can be regarded as text, which is constituted in the form of symbols[14]. The meanings of these symbols depend on each other's related system, which are composed of symbols and can be analyzed and decoded with the semiotic method. Thus, Roland Barthes applied semiotics to cultural studies and based on Saussure's Semiotics, put forward the research theory of two orders of signification. And he believed that any one symbol has symbolic connotation of different levels. The first level is denotation, including the signifier and signified of the first level, usually referring to the more obvious sense of the symbol itself; the second level is connotation, including the denotation signifier formed in the first level and another symbolic signified, and this symbolic connotation is used to interact with people's cultural feelings.

\section{Construction of design modes and application of cultural and creative products}

\subsection{Construction of design modes of cultural and creative products}

Based on the two orders of signification of Roland Barthes semiotics, in this study, the dominant meme of ceramics in Liao Dynasty corresponds to the first level denotation of two orders of signification; and then the denotative signifier of the first level dominant meme and the signified of the recessive meme constitute the connotation of the second level symbol; and according to the connotation of the second level, the cultural and creative product design with dominant and recessive meme of ceramics in Liao dynasty is completed. In the stage of design practice, in an experimental way, the extensional signifier (visual symbol design) is finished with the method of formal constitution according to signifier and signified of dominant meme in the first level. On this basis, according to the signified in the second level, the final cultural and creative product design is finished with the method of association and metaphor. The specific design mode is shown in Figure 1. 


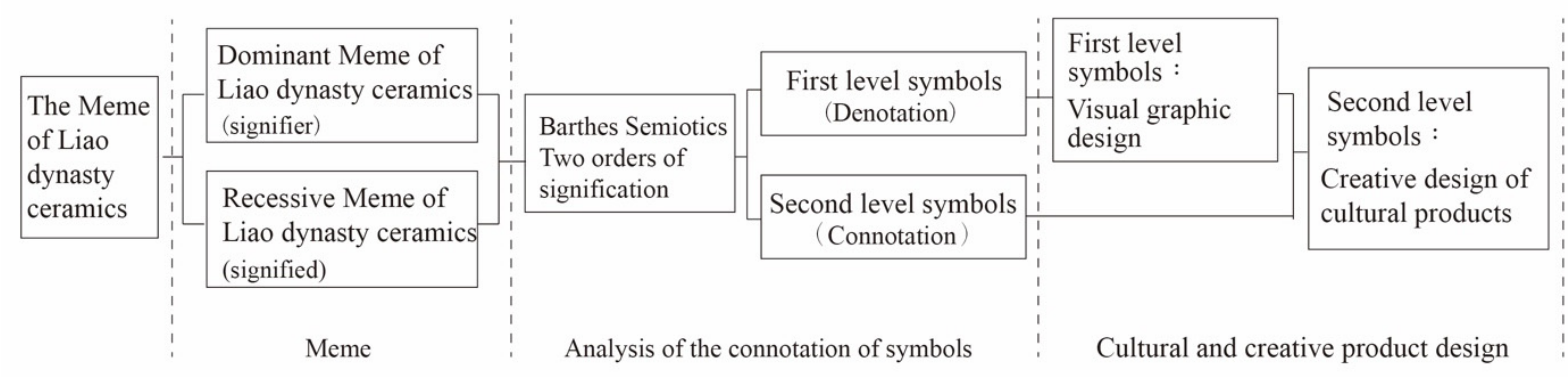

Figure.1 The Design Method of Cultural Products Based on the Meme

\subsection{Meme of ceramics in the Liao dynasty}

Based on Dawkins' meme theory and the characteristics of dominant and recessive genes in biology, in this research, meme is divided into dominant meme and recessive meme. And according to three levels of cultural space proposed by Leong \& Clark[15]: external "visible" level; intermediate "behavior" level; internal "invisible" level, it is proposed that "external visible level" in the cultural space corresponds to dominant meme, including, visual information of patterns, colors and shapes of ancient artifacts, and "intermediate behavior level" and "internal invisible level" in the cultural space correspond to recessive meme, including the use situation, use function, historical information, folk allusions and other literal information of ancient artifacts. The specific corresponding relationships are shown in Figure 2 .

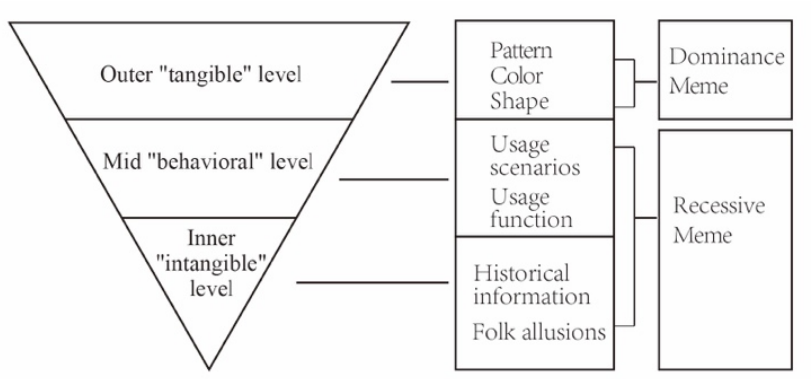

Figure. 2 The spatial perspective of culture $\&$ Meme attribute

In this research, a kind of ceramic in Liao dynasty was selected which could better reflect the multicultural integration. This ceramic is preserved in the Palace Museum, and is called "white glaze engraved flowery spout pot". The design of this pot not only has the characteristics of long neck bottle, pouring pot in the Central Plains (Northern Song Dynasty), but also based on which, integrates the modeling features of Phoenix bottle, a unique shape of Qidan nationality in the North (Liao Dynasty), so as to forms a unique shape in the Liao dynasty. Its style not only has the regional and functional characteristics of the nomadic people in the north, as well as the elegant image of ceramic in the Song Dynasty.
Therefore, in this research, with the above-mentioned shape as the research sample, according to the visual information attributes contained in the above dominant meme, the meme of ceramics in the Liao dynasty is extracted, including patterns, shape, colors and other dominant memes. Then through collection and analysis of relevant literature of this sample, the recessive meme is extracted, including basic information, modeling information, functional information and historical information. The specific extraction result of "white glaze engraved flowery spout pot" in the Liao dynasty is shown in Table 1.

Table 1. Meme of ceramics in the Liao dynasty.

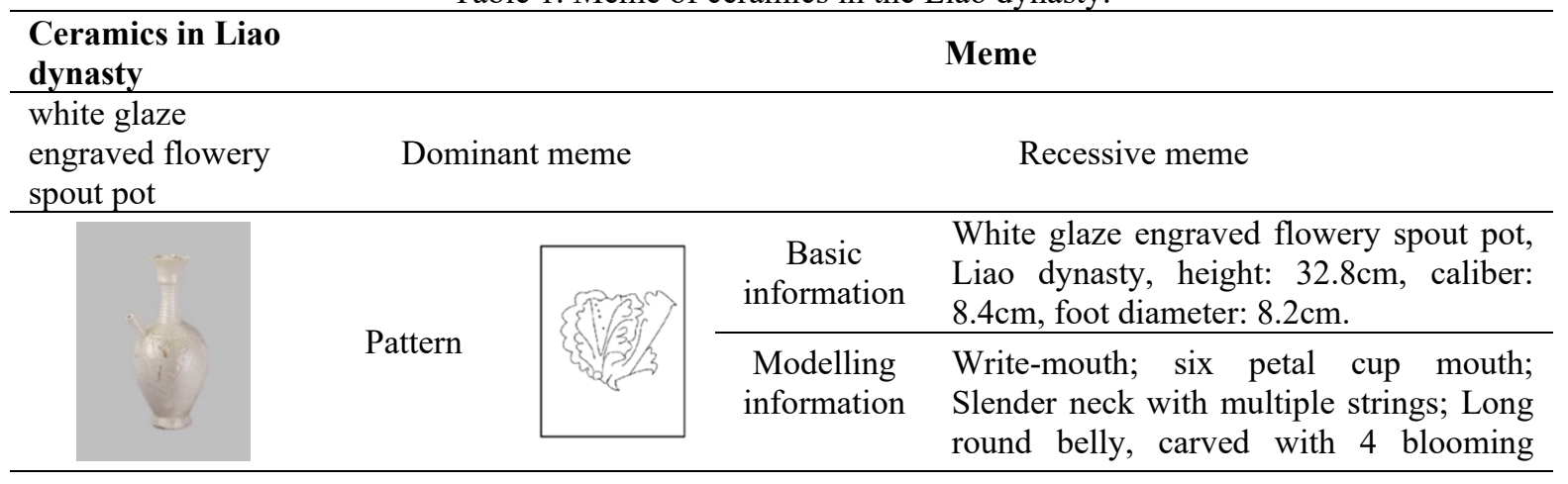




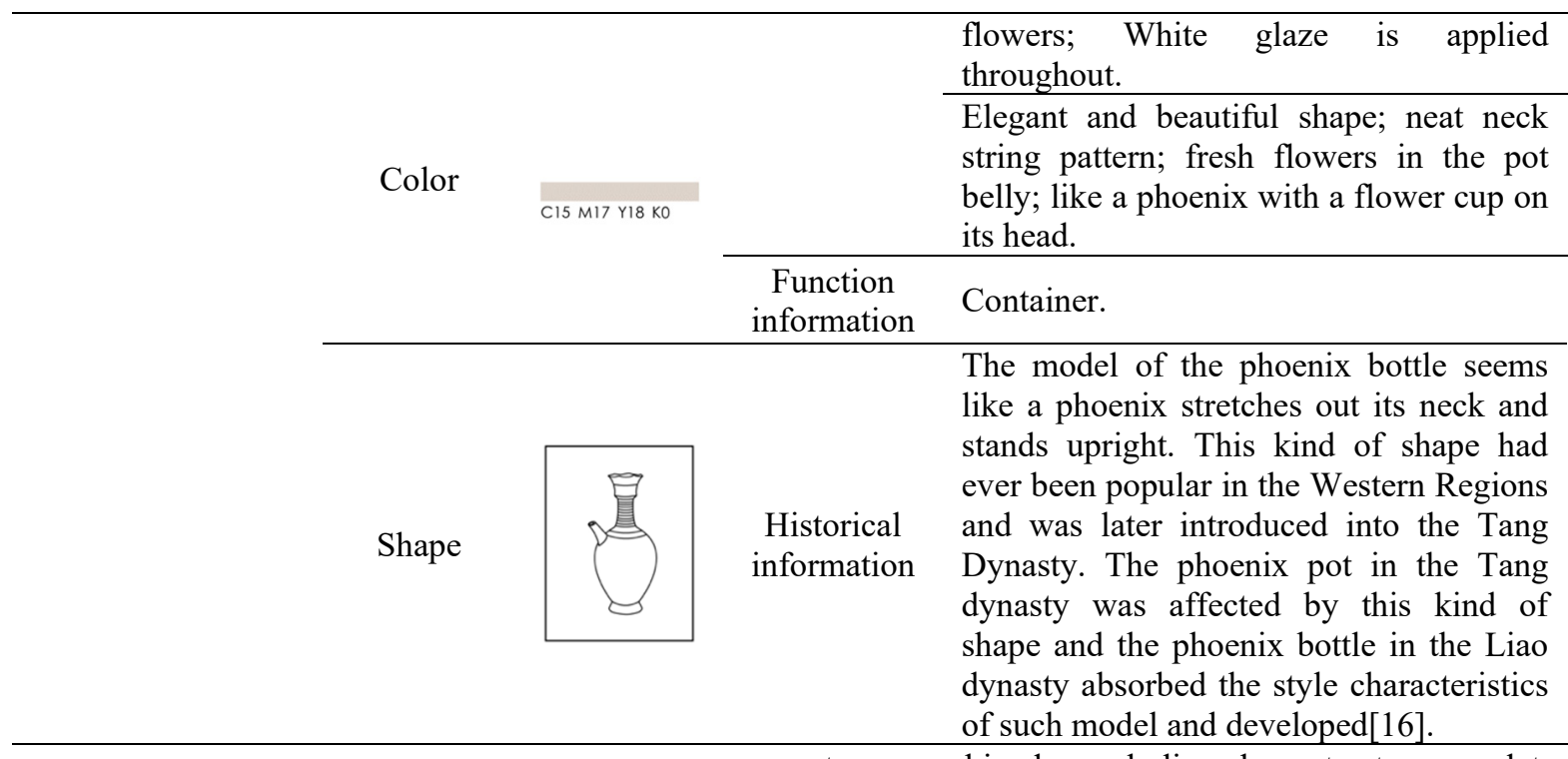

\subsection{The design application of the design modes of cultural and creative products}

In the design of cultural and creative products, first, the visual symbol of dominant gene is analyzed. With the two orders of signification of Roland Barthes semiotics as research structure, the meaning of the first-level extended symbols is analyzed through the signifier and signified of dominant meme. The method of modern constitution is combined to reorganize flower plant pattern genes, and through copying, contrasting, rotating and other design techniques, the traditional square continuous pattern formation is used to redesign the visual symbol of pattern gene. And color gene is applied to recombined symbolic elements to complete the extensional signifier in the first level so as to convey the cultural characteristics of dominant meme of ceramics in the Liao dynasty through this design and metaphorize people's good vision for life. Second, referring to the extensional signifier of symbols in the first level, namely, the signifier in the second level; at the same time, integrating the cultural connotation meaning of the recessive meme of the ceramics in the Liao dynasty, that is, the signified in the second level, which constitutes the symbolic connotation in the second level. And this will be used as the source of inspiration for the final cultural and creative product design concept, which has design patterns and design applications, as shown in Figure 3 .

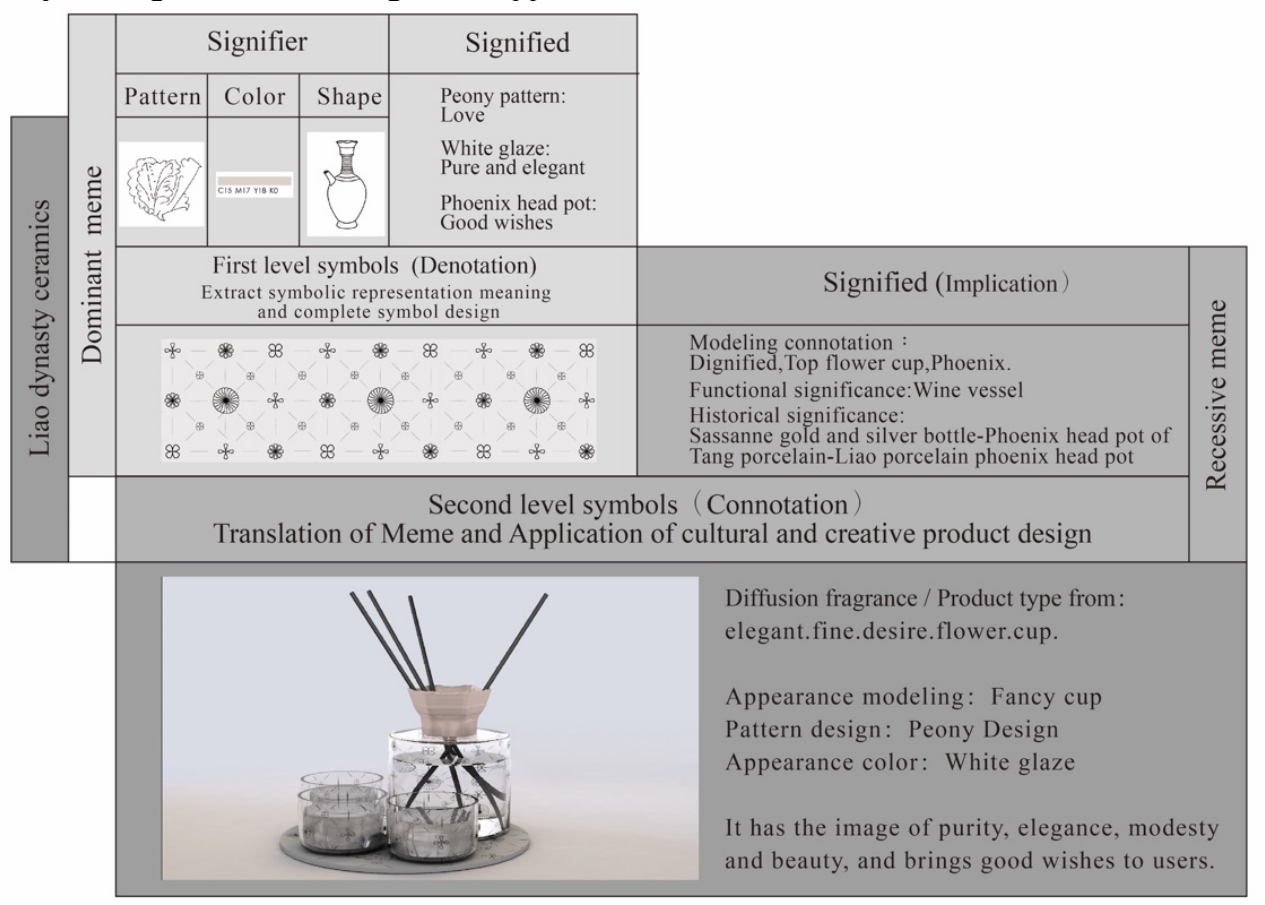

Figure.3 Two orders of signification paraphrase \& Design application

The creative ideas are as follows: the category and function of the cultural and creative products need refer to signified"pure and elegant, beautiful wishes"in the second level; and the modelling implication "fresh flowers" of signified as well as function implication "container" in the second level so as to extract cultural 
information "elegance, wishes, flowers and container" and translate the meme into corresponding cultural and creative product, namely, "Diffusion cashmeran and scented candle holder". Thus, this kind of cultural and creative products not only have function but also embody the meaning of a better life. For the design of cashmeran, based on the modelling implication "with flower cup on the head and flowers on the belly" of the recessive meme of signified in the second level, through direct translation, the top of the Cashmeran is designed as flower cup. In the pattern of cashmeran and candle holder, the extensional signifier of symbol in the first level is partially applied in the cultural and creative products. In color design, the ceramic sample glaze-milky white color is extracted from dominant color gene is applied in the flower cup on the top of cashmeran. Through the translation of such design mode, the cultural and creative products not only have dominant meme of "white glaze engraved flowery spout pot" in the Liao dynasty, but also integrate recessive meme connotation not limited to appearances, so that the design of the cultural and creative products embodies not only "external visible level", but also "intermediate behavior level" and the "internal invisible level", and arouses consumers' emotional resonance for cultural and creative products. This research expects to effectively extract and translate the meme of the ancient artifacts and apply in the design development of cultural and creative products with the ancient artifacts as the creative source of design.

\section{Conclusion}

The meaning and representation of meme constitute the core content of cultural code. People can only know the social cultural connotation and feel their resonance with this culture through common culture code. This research starts from Dawkins' meme theory and analogizes the concept of genes in biology to the transfer of cultural genes so as to extract meme of ceramics in the Liao dynasty from dominant and recessive meme. It also explores the extensional cultural connotation of dominant and recessive meme of the ceramics in the Liao dynasty through the analysis system mode of two orders of signification of Roland Barthes semiotics, and translate it into design elements and connotation so as to apply in the development and design of cultural and creative products. Moreover, on this basis, the cultural and creative product design innovation models based on meme is constructed. Compared with the past cultural and creative product design directly presented by focusing on entity representation of external cultural level of the ancient artifacts, this kind of mode contains the translation of cultural connotation of intermediate behavior level and internal intangible level and makes cultural and creative products contain connotation representation of meme of ancient artifacts. As for those designers of cultural and creative products who love to find creation source from the ancient artifacts, this research tries to provide a kind of design mode for reference. Expects to translate the meme of ancient artifacts into the cultural and creative products embodying cultural connotation through this design mode so as to arouse the emotional resonance of consumers for cultural and creative products.

\section{References}

1. Lin, R. T. (2007) Transforming Taiwan aboriginal cultural features into modern product design: A case study of a cross-cultural product design model. International Journal of Design, 1(2): 45-53.

2. Hsu, C. H., Lin, R.T. (2011) A Study on Cultural Product Design Process. Journal of Design, 16(4):118.

3. Luo, S. J., Dong, Y. N. (2017) Role of cultural inspiration with different types in cultural product design activities. International Journal of Technology and Design Education, 27(3), 499-515.

4. Ye, Z. M. (2011) Chinese Ceramic History. SDX Joint Publishing Company.

5. Wang, X., Zhao, C. M. (2018) Design Analysis of Ceramic Molding in Liao Dynasty. Packaging Engineering, 39(16):243-247.

6. Dawkins, R. (1976) The selfish gene. New York, NY: Oxford university press.

7. Lang, L. N. (2017) The Concept and History of Culture Gene Studies. Journal of Guangxi University for Nationalities(Philosophy and Social Science Edition), (02):14-19.

8. Liu, P. L. (2012) On Construction and Utilization of Chinese Traditional Settlements Landscape's Genetic Map. Peking University.

9. Gou, B.C., Yu, H., Li, Z. F., Chen, L.L., Wang,W.W.(2011) Study on Gene Extraction, Design and Application of Banpo Painted Pottery Culture . Journal of Northwestern Polytechnical Universtty (Social Sciences), 31(4):66-69.

10. Wang, H.H., Hung, J. L. (2011) A Metaphorical Method for Product Design in Cultural and Creative Industry. Journal of Design, 16(4), 35-55.

11. Zhang, M., Liu, L., Xiong, Z,Y.(2016) Application of Scenario-based Methods in Product Design of Cultural Image . Packaging Engineering, (22):164168.

12. Zhu, S. S., Luo, S. J.(2013) Re-creation of heritage elements based on design semiotics in product design. Journal of Zhejiang University(Engineering Science), (11):2065-2072.

13. Wang,W.W., Wei,T.(2018) Redesign and Application of the Triangle Pattern of Banpo. Packaging Engineering, 39(8):42-46.

14. Barthes, R. (1957) Mythologies. New York: Hill \& Wang.

15. Leong, B. D., Clark, H. (2003) Culture-based knowledge towards new design thinking and practice-A. dialogue. Design Issues, 19(3): 48-58.

16. Peng, S. G., Gao, Y. F.(2018)The Date and Issues on The 'Liao-dynasty' White-Glazed Ceramics with 
Black Carved Pattern . Palace Museum Journal, 199(05):79-87+160. 